Published in final edited form as:

J Org Chem. 2006 March 3; 71(5): 2181-2184.

\title{
Synthesis and Characterization of the Oxidized dGTP Lesions Spiroiminodihydantoin-2'-deoxynucleoside-5'-triphosphate and Guanidinohydantoin-2'-deoxynucleoside-5'-triphosphate
}

\author{
Yu Ye, James G. Muller, and Cynthia J. Burrows \\ Department of Chemistry, University of Utah, Salt Lake City, Utah 84112, burrows@chem.utah.edu
}

\begin{abstract}
Two convenient synthetic routes to the oxidized guanosine triphosphate lesions spiroiminodihydantoin-2'-deoxynucleoside-5'-triphosphate (dSpTP) and guanidinohydantoin-2'deoxynucleoside-5'-triphosphate (dGhTP) are reported. Both two-electron oxidation of 2'deoxy-7,8-dihydro-8-oxoguanosine-5'-triphosphate (dOGTP) using $\mathrm{SO}_{4}{ }^{-2}$ generated photolytically from $\mathrm{K}_{2} \mathrm{~S}_{2} \mathrm{O}_{8}$, or four-electron oxidation of 2'-deoxyguanosine-5'-triphosphate (dGTP) from singlet oxygen provide either dSpTP or dGhTP at pH 8.0 or 4.4 , respectively. Highly purified triphosphates are obtained by ion pair reversed-phase HPLC.
\end{abstract}

Oxidative damage occurring at DNA bases has been the focus of considerable interest during the past decade owing to its implications in mutagenesis, carcinogenesis and aging. ${ }^{1-3}$ DNA and the nucleotide triphosphate (dNTP) pool are subject to damage by both endogenous and exogenous agents resulting in DNA strand breaks, abasic sites, DNA-protein cross-links, and oxidized bases that require DNA repair enzymes to maintain the integrity of the genome. ${ }^{2}$ Recent studies demonstrated that key intermediates in the oxidation of guanosine $(\mathrm{G})$ as well as its common oxidation product 7,8-dihydro-8-oxoguanosine (OG) which is sensitive to further oxidation, are susceptible to adduction by nucleophiles including water, ${ }^{4}$ alcohols, ${ }^{5}$ peroxynitrite, ${ }^{6}$ polyamines, ${ }^{7}$ amino acids and proteins. ${ }^{8}$ When $\mathrm{H}_{2} \mathrm{O}$ serves as the nucleophile, the products spiroiminodihydantoin $(\mathrm{Sp})$ and guanidinohydantoin $(\mathrm{Gh})$ have been unambiguously identified from both $\mathrm{G}$ and $\mathrm{OG}$ oxidation (Scheme 1). ${ }^{4,9-17}$ Our previous work has demonstrated that $\mathrm{Sp}$ is the thermodynamic product in nucleosides under neutral or slightly basic conditions, while $\mathrm{Gh}$ is preferred at $\mathrm{pH}<6$ in nucleosides or near neutral $\mathrm{pH}$ in oligomers. ${ }^{9,10,12,18}$ Both $\mathrm{Sp}$ and $\mathrm{Gh}$ are proposed to derive from the common intermediate 5-OH-OG, an analog of which has been characterized at low temperature by Foote and coworkers. ${ }^{19}$ Rearrangement of 5-OH-OG to Sp requires a 1,2-acyl shift that is favorable for the unencumbered nucleoside, but is hindered in base-stacked oligomers. Formation of Gh follows the same pathway as uric acid oxidation to allantoin; 20 in this mechanism, hydration at $\mathrm{C} 6$ and cleavage of the $\mathrm{C} 6-\mathrm{N} 1$ bond is facilitated by protonation of the guanidine group at lower $\mathrm{pH}$. Decarboxylation then leads to Gh.

Previous in vivo 21 and in vitro ${ }^{22,23}$ mutagenesis assays indicate that both $\mathrm{Sp}$ and $\mathrm{Gh}$ are $>98 \%$ mutagenic and cause $\mathrm{G}$ to $\mathrm{C}$ and $\mathrm{G}$ to $\mathrm{T}$ transversions, whereas $\mathrm{OG}$ is only about 5\% mutagenic leading to G-T transversions. The mutagenicity of dOGTP originates with its incorporation into duplex DNA by various polymerases, 24,25 although this process can be prevented by repair enzymes such as E. coli MutT and its human homolog hMTH which hydrolyze dOGTP to dOGMP. ${ }^{26,27}$ However, it has been recently argued by Mathews that dOGTP may not be the best substrate of MutT. ${ }^{28}$ Due to the lower redox potential of OG ( 0.5 
V lower than G), ${ }^{29}$ dOGTP may be oxidized to spiroiminodihydantoin-2'-deoxynucleoside-5'triphosphate (dSpTP) and to a lesser extent guanidinohydantoin-2'-deoxynucleoside-5'triphosphate (dGhTP) under physiological conditions. Therefore, it is of current interest to study how cells process dSpTP and dGhTP including their incorporation into replicating DNA by polymerases and their hydrolysis by the DNA repair enzymes MutT and hMTH. These studies depend on the syntheses of dSpTP and dGhTP which we report herein.

A common synthetic method for modified nucleoside triphosphates involves phosphorylation of the modified nucleoside by chemical or enzymatic methods. ${ }^{30-32}$ Chemical phosphorylation typically involves treatment with phosphoryl chloride and subsequent displacement of the chloride with pyrophosphate, introducing reagents that may not be compatible with the sensitive glycosidic bonds of the $\mathrm{Sp}$ and $\mathrm{Gh}$ nucleosides. In addition, efficient enzymatic phosphorylation generally requires strong binding between the enzyme and substrate; this interaction has been shown to be sensitive to the nature of the purine or pyrimidine base. For example, OGMP cannot be phosphorylated enzymatically by guanylate kinase. ${ }^{32}$ Furthermore, each of the above synthetic routes requires multiple purification steps that complicate the synthesis and reduce the overall yield. Based on the above concerns, we chose to start the synthesis of dSpTP and dGhTP with the triphosphates groups already present using commercially available dGTP and dOGTP.

The major difficulty associated with the synthesis of dSpTP and dGhTP from dGTP or dOGTP was anticipated to be the removal of salts from low molecular weight organic polyanions. In addition, a small amount of contamination from the starting dNTP could result in misleading polymerase data, so we devised synthetic routes that would generate dSpTP and dGhTP from either dOGTP or dGTP. Synthesis of dSpTP and dGhTP from both triphosphates precursors allows one to test for erroneous enzymatic results caused by trace contaminants that are better enzyme substrates. In this paper, we describe the first synthesis and characterization of dSpTP and dGhTP.

Previous work in our lab documented the formation of $\mathrm{Gh}$ and $\mathrm{Sp}$ by the oxidation of OG nucleoside with $\mathrm{Na}_{2} \mathrm{IrCl}_{6} \cdot 4,9,10,22$ However, this method cannot be applied to the Gh and Sp triphosphate synthesis due to the difficulties of removing iridium salts, and the pathway is low yielding when conducted with $\mathrm{G}$ as the starting material. Alternatively, Sp and Gh nucleosides can be synthesized by singlet oxygen oxidation of guanosine under controlled $\mathrm{pH}$ conditions. 12

In the present work, synthesis of dSpTP, from commercially available dOGTP, proved to be the most efficient method. While numerous oxidants can be used to convert OG to Sp or Gh, we found that potassium persulfate, generating sulfate radical under UV photolysis, is the most advantageous route since it produces potassium sulfate as a benign side product. The $\mathrm{pH}$ dependent results obtained (Scheme 2) were consistent with those previously observed for the oxidation of $O$-protected $\mathrm{OG}$ or $\mathrm{G}$ nucleosides by either $\mathrm{Na}_{2} \mathrm{IrCl}_{6}{ }^{9}$ or singlet oxygen. ${ }^{12}$ With $O$-protected guanosine as substrate, singlet oxygen as well as hypochlorous acid both yield $\mathrm{Sp}$ at $\mathrm{pH}>6$ and $\mathrm{Gh}$ at $\mathrm{pH}<6 .{ }^{16}$ Similar $\mathrm{pH}$ effects were also observed previously for the oxidation of $O$-protected OG nucleoside by peroxynitrite or $\mathrm{CoCl}_{2} / \mathrm{KHSO}_{5} .{ }^{3}$ However, Henderson and coworkers recently reported that $\mathrm{Gh}$ was the major product for the oxidation of $\mathrm{dOG}$ at all $\mathrm{pH}$ values ranging from 4.6 to 8.4 at $22^{\circ} \mathrm{C}$, while $\mathrm{Sp}$ is the main product only at higher temperatures $\left(\mathrm{pH} 7.2,65^{\circ} \mathrm{C}\right),{ }^{33}$ suggesting that there could be an effect of an unprotected $5^{\prime}-\mathrm{OH}$ on the partitioning between $\mathrm{Gh}$ and $\mathrm{Sp}$.

Purification of dGhTP and dSpTP is accomplished by a combination of size exclusion and ion pair chromatography. Since dSpTP and dGhTP do not have strong UV absorptions at $260 \mathrm{~nm}$, traditional ion exchange chromatography using high salt could not be employed for the 
purification of dSpTP and dGhTP. Therefore, we turned to ion pair chromatography 34 to analyze and purify dSpTP and dGhTP. The use of the ion pair reagents, tetrabutylammonium sulfate (TBS) or tetrabutylammonium acetate (TBAA), in conjunction with a C18 reversedphase column, allows the separation of anions with little background absorption at $220 \mathrm{~nm}$. The two diastereomers of dSpTP were separated using ion pair chromatography, although their absolute configurations have not yet been assigned. The UV-Vis spectra of dSpTP shown on ion pair chromatography were consistent with what was previously obtained for the Sp nucleoside. ${ }^{4}$ After initial desalting by size exclusion chromatography, the purity was observed to be approximately $90 \%$ for dGhTP and $95 \%$ for dSpTP. After ion pair HPLC purification, dSpTP was $99 \%$ pure (see Fig. 1). The reaction yield of dSpTP was $75 \%$ prior to chromatography, and the final purified yield of dSpTP was 50\%. Note that dGhTP is also formed as a mixture of 2 diastereomers, but we have previously shown that these interconvert over a period of hours via enolization of the hydantoin ring. 9,12

An alternate synthetic approach from dGTP involved its oxidation by ${ }^{1} \mathrm{O}_{2}$ at various $\mathrm{pH}$ values. Under acidic conditions ( $\mathrm{pH} 4.4$ ), dGhTP was formed preferentially while dSpTP was generated at slightly basic conditions (pH 8.0). The purity of dSpTP was approximately $90 \%$ after purification by size exclusion chromatography, and the overall purified yield was estimated to be $35 \%$.

The purified dSpTP was analyzed by various MS experiments in comparison to prior studies with protected nucleosides. ${ }^{4}$ ESI/MS results showed masses corresponding to dSpTP, dSpDP and dSpMP (Figure 2). We speculated that dSpTP was undergoing fragmentation generating $\mathrm{dSpDP}$ and dSpMP during ESI/MS analysis. To test this theory, a parent ion ESI/MS experiment was preformed, which unambiguously demonstrated that the dSpDP ion was derived from dSpTP. Furthermore, the identity of dSpTP was confirmed by an MS fragmentation experiment. This experiment consisted of selectively cleaving the glycosidic bond and subsequently forming the free nucleobase. The fragmentation pattern was consistent with the results formerly obtained for Sp nucleoside. ${ }^{4}$ In addition, an LC-ESI/MS experiment of dSpTP indicated that the two diasteromers of dSpTP eluted at $21 \mathrm{~min}$. with a corresponding mass of 538, along with masses associated with dSpDP and dSpMP. Similarly, the LC-ESI/ MS results associated with a crude dGhTP sample revealed the masses of dGhTP, dGhDP and dGhMP at $19 \mathrm{~min}$. From these studies, we conclude that the triphosphate moiety remains intact during synthesis and purification, and that fragmentation to diphosphates and monophosphates only occurs in the mass spectrometer during analysis.

NMR experiments were also conducted, and the ${ }^{31} \mathrm{P}$ NMR of dSpTP showed three clusters of peaks corresponding to $\alpha, \beta$ and $\gamma$ phosphorous atoms. The splitting pattern suggested that the 2 doublets at $-4.6 \mathrm{ppm}$ were derived from the two $\alpha^{31} \mathrm{P}$ of the diastereomers in contrast to the doublet observed for ATP. ${ }^{35}$ The $\gamma$ P at the terminus is expected to be the least perturbed by the presence of diasteromers and is observed to be two peaks at $-9.2 \mathrm{ppm}$. Furthermore, the ${ }^{31} \mathrm{P}$ NMR associated with the $\beta$ phosphorous was complicated by the splitting by both $\alpha^{31} \mathrm{P}$ and $\gamma^{31} \mathrm{P}$ and appeared as a broad multiplet at $-17.8 \mathrm{ppm}$.

The Heteronuclear Multiple Bond Correlation (HMBC) NMR experiment of 2',3',5'-triOacetylspiroiminodihydantoin (SpOAc) demonstrated the correlation of $\mathrm{H}^{\prime}$ proton with the $\mathrm{C} 2$ carbonyl on the hydantoin ring, which was reported by Adam and coworkers for the spiroiminodihydantoin $2^{\prime}$-deoxynucleoside. ${ }^{14}$ The resonance for the $\mathrm{H} 1$ ' proton was assigned based on the fact that it is the only doublet in the sugar region. The same correlation of the H1' proton and $\mathrm{C} 2$ carbonyl of the hydantoin ring was also found for the $2^{\prime}, 3^{\prime}, 5^{\prime}$-tri- $O$ acetylguanidinohydantoin (GhOAc, see Supporting Information). The HMBC of the dinucleoside monophosphate $(\mathrm{d}(\mathrm{GhpT}))$ containing Gh has been reported previously, ${ }^{15}$ but the correlation between the $\mathrm{H} 1$ ' proton and the $\mathrm{C} 2$ carbonyl carbon of the hydantoin ring was 
not observed. The results of the current NMR study support the structures of Sp and Gh as assigned based upon mass spectroscopy plus ${ }^{13} \mathrm{C}$ and ${ }^{15} \mathrm{~N}$ NMR experiments. ${ }^{4,12}$

In conclusion, we have described effective methods to prepare highly purified dSpTP. Our protocol involves oxidation of either $\mathrm{G}$ by singlet oxygen or OG by potassium persulfate, desalting by size exclusion chromatography and purification by ion pair chromatography. The purified dSpTP will be utilized in subsequent enzymatic studies. The same methods are applicable to dGhTP by lowering the $\mathrm{pH}$ of the solution, although the yield is lower than that of dSpTP. The cellular relevance of Sp has recently been reported for repair deficient $E$. coli cells under oxidative stress, ${ }^{36}$ and this finding spurs further interest in determining the molecular basis for the high mutagenicity of these lesions.

\section{Experimental Section}

\section{Synthesis of spiroiminodihydantoin-2'-deoxynucleoside-5'-triphosphate (dSpTP) from 2'- deoxyguanosine-5'-triphosphate (dGTP) and 7,8-dihydro-8-oxo-2'-deoxyguanosine-5'- triphosphate (dOGTP)}

A solution consisting of dOGTP $(0.04 \mathrm{mg}, 0.08 \mu \mathrm{mol}), 100 \mu \mathrm{L}$ of $40 \mathrm{mM} \mathrm{K}{ }_{2} \mathrm{~S}_{2} \mathrm{O}_{8}(1.1 \mathrm{mg}, 4$ $\mu \mathrm{mol})$ dissolved in $75 \mathrm{mM}$ potassium phosphate $(\mathrm{pH} 8.0$, adjusted with $\mathrm{NaOH}$ ), was irradiated at a distance of 7-8 $\mathrm{cm}$ with a short wavelength UV lamp for $30 \mathrm{~min}$ at room temperature (yield $75 \%$ ). The resulting solution was passed through a Sephadex G-25 column to remove salts. The resultant fractions were further purified by ion pair HPLC with a $4.6 \mathrm{~mm} \times 250 \mathrm{~mm} \mathrm{C}-18$ reversed phase column and a gradient solvent system consisting of $5 \%$ solvent $\mathrm{B}$ to $20 \%$ solvent B over $40 \mathrm{~min}$. Solvent A consisted of $5 \mathrm{mM}$ tetrabutylammonium sulfate and $10 \mathrm{mM}$ sodium phosphate $(\mathrm{pH} 7)$ while Solvent B was acetonitrile. The flow rate was $1 \mathrm{~mL} \mathrm{~min}^{-1}$. The UV spectra were recorded at $220 \mathrm{~nm}$. Overall yield $\approx 50 \%$.

Alternatively, a solution consisting of dGTP $(2 \mathrm{mg}, 4 \mu \mathrm{mol}), 1 \mathrm{~mL}$ of $0.3 \mathrm{mM}$ Rose Bengal $(0.3 \mathrm{mg}, 300 \mu \mathrm{mol})$ dissolved in $75 \mathrm{mM}$ potassium phosphate $(\mathrm{pH} 8.0)$, was incubated at $4{ }^{\circ} \mathrm{C}$ in a water bath for $5 \mathrm{~min}$ followed by irradiation at a distance of 7-8 $\mathrm{cm}$ with a high intensity sunlight lamp (wavelength $>500 \mathrm{~nm}$ ) for $3 \mathrm{hr}$. The resulting solution was passed through a Sephadex G-25 column to remove the Rose Bengal. The resultant fractions were further purified by ion pair HPLC with a $4.6 \mathrm{~mm} \times 250 \mathrm{~mm} \mathrm{C}-18$ reversed phase column and a gradient solvent system consisting of $5 \%$ solvent B to $20 \%$ solvent B over 40 min. Solvent A consisted of $5 \mathrm{mM}$ tetrabutylammonium sulfate and $10 \mathrm{mM}$ sodium phosphate $(\mathrm{pH} 7)$ while Solvent $\mathrm{B}$ was acetonitrile. The flow rate was $1 \mathrm{~mL} \mathrm{~min}^{-1}$. The UV spectra were recorded at $220 \mathrm{~nm}$. Overall yield $\approx 35 \%$. ${ }^{31} \mathrm{P}$ NMR $\left(\mathrm{H}_{2} \mathrm{O}\right) \delta-17.8(\mathrm{br}),-9.3(\mathrm{~s}),-9.2(\mathrm{~s}),-4.6(\mathrm{~d}, \mathrm{~J}=36 \mathrm{~Hz}),-4.5$ $(\mathrm{d}, \mathrm{J}=36 \mathrm{~Hz})$. Negative ion ESI-MS, $m / z 538[\mathrm{M}-\mathrm{H}]^{-} . \lambda_{\max }\left(\mathrm{H}_{2} \mathrm{O}\right)=230 \mathrm{~nm}$.

\section{Synthesis of guanidinohydantoin-2'-deoxynucleoside-5'-triphosphate (dGhTP) from 2'- deoxyguanosine-5'-triphosphate (dGTP) and 7,8-dihydro-8-oxo-2'-deoxyguanosine-5'- triphosphate (dOGTP)}

A solution consisting of dOGTP $(0.04 \mathrm{mg}, 0.08 \mu \mathrm{mol}), 100 \mu \mathrm{L}$ of $40 \mathrm{mM} \mathrm{K}{ }_{2} \mathrm{~S}_{2} \mathrm{O}_{8}(1.1 \mathrm{mg}, 4$ $\mu \mathrm{mol}$ ) dissolved in $75 \mathrm{mM}$ potassium phosphate ( $\mathrm{pH} 4.4$ ), was irradiated at a distance of 7-8 $\mathrm{cm}$ with a short wavelength UV lamp for $30 \mathrm{~min}$ a room temperature (yield $50 \%$ ). The resulting solution was passed through a Sephadex G-25 column to remove salts. The resultant fractions were further purified by ion pair HPLC with a $4.6 \mathrm{~mm} \times 250 \mathrm{~mm}$ C-18 Nuc reversed phase column and a gradient solvent system consisting of 5\% solvent B to $20 \%$ solvent B over 40 min. Solvent A consisted of $5 \mathrm{mM}$ tetrabutylammonium sulfate and $10 \mathrm{mM}$ sodium phosphate (pH 7) while Solvent B was acetonitrile. The flow rate was $1 \mathrm{~mL} \mathrm{~min}{ }^{-1}$. The UV spectra were recorded at $220 \mathrm{~nm}$. 
Alternatively, a solution consisting of dGTP $(2 \mathrm{mg}, 4 \mu \mathrm{mol}), 1 \mathrm{~mL}$ of $0.3 \mathrm{mM}$ Rose Bengal $(0.3 \mathrm{mg}, 300 \mu \mathrm{mol})$ dissolved in $75 \mathrm{mM}$ potassium phosphate $(\mathrm{pH} 4.4)$, was incubated at $4{ }^{\circ} \mathrm{C}$ in a water bath and irradiated at a distance of $7-8 \mathrm{~cm}$ with a high intensity sunlight lamp (wavelength $>500 \mathrm{~nm}$ ) for $3 \mathrm{hr}$. The resulting solution was passed through a Sephadex G-25 column to remove the Rose Bengal. The resultant fractions were further purified by ion pair HPLC with a $4.6 \mathrm{~mm} \times 250 \mathrm{~mm}$ C- 18 reversed phase column and a gradient solvent system consisting of 5\% solvent B to $20 \%$ solvent B over $40 \mathrm{~min}$. Solvent A consisted of $5 \mathrm{mM}$ tetrabutylammonium sulfate and $10 \mathrm{mM}$ sodium phosphate $(\mathrm{pH} 7)$ while Solvent B was acetonitrile. The flow rate was $1 \mathrm{~mL} \mathrm{~min}^{-1}$. The UV spectra were recorded at $220 \mathrm{~nm}$. Negative ion ESI-MS, $m / z 512[\mathrm{M}-\mathrm{H}]^{-} \cdot \lambda_{\max }\left(\mathrm{H}_{2} \mathrm{O}\right)=225 \mathrm{~nm}$.

Further characteration of dSpTP and dGhTP are based on HMBC and ESI-MS/MS experiments compared to nucleosides. See Supporting Information.

\section{Supplementary Material}

Refer to Web version on PubMed Central for supplementary material.

\section{Acknowledgements}

This work was supported by a grant from the NIH (CA090689).

\section{References}

1. Burrows CJ, Muller JG. Chem Rev 1998;98:1109-1152. [PubMed: 11848927]

2. Beckman KB, Ames BN. Mutat Res 1999;424:51-58. [PubMed: 10064849]

3. Wang D, Kreutzer DA, Essigmann JM. Mutat Res 1998;400:99-115. [PubMed: 9685598]

4. Luo W, Muller JG, Rachlin EM, Burrows CJ. Org Lett 2000;2:613-616. [PubMed: 10814391]

5. Niles JC, Wishnok JS, Tannenbaum SR. Chem Res Toxicol 2004;17:1501-1509. [PubMed: 15540948]

6. Yu H, Niles JC, Wishnok JS, Tannenbaum SR. Org Lett 2004;6:3417-3420. [PubMed: 15355066]

7. Hosford ME, Muller JG, Burrows CJ. J Am Chem Soc 2004;126:9540-9541. [PubMed: 15291548]

8. Johansen ME, Muller JG, Xu X, Burrows CJ. Biochemistry 2005;44:5660-5671. [PubMed: 15823024]

9. Luo W, Muller JG, Rachlin EM, Burrows CJ. Chem Res Toxicol 2001;14:927-938. [PubMed: 11453741]

10. Luo W, Muller JG, Burrows CJ. Org Lett 2001;3:2801-2804. [PubMed: 11529760]

11. Sugden KD, Campo CK, Martin BD. Chem Res Toxicol 2001;14:1315-1322. [PubMed: 11559048]

12. Ye Y, Muller JG, Luo W, Mayne CL, Shallop AJ, Jones RA, Burrows CJ. J Am Chem Soc 2003;125:13926-13927. [PubMed: 14611206]

13. Niles JC, Wishnok JS, Tannenbaum SR. Org Lett 2001;3:963-966. [PubMed: 11277770]

14. Adam W, Arnold MA, Grune M, Nau WM, Pischel U, Saha-Moller CR. Org Lett 2002;4:537-540. [PubMed: 11843585]

15. Chworos A, Seguy C, Pratviel G, Meunier B. Chem Res Toxicol 2002;15:1643-1651. [PubMed: 12482248]

16. Suzuki T, Friesen MD, Ohshima H. Chem Res Toxicol 2003;16:382-389. [PubMed: 12641439]

17. Crean C, Geacintov NE, Shafirovich V. Angew Chem Int Ed 2005;44:5057-5060.

18. Leipold MD, Muller JG, Burrows CJ, David SS. Biochemistry 2000;39:14984-14992. [PubMed: 11101315]

19. McCallum JEB, Kuniyoshi CY, Foote CS. J Am Chem Soc 2004;127:16777-16782. [PubMed: 15612716]

20. Sokolic S, Modric N, Poje M. Tetrahedron Lett 1991;32:7477-7480.

21. Henderson PT, Delaney JC, Muller JG, Neeley WL, Tannenbaum SR, Burrows CJ, Essigmann JM. Biochemistry 2003;42:9257-9262. [PubMed: 12899611] 
22. Kornyushyna O, Berges AM, Muller JG, Burrows CJ. Biochemistry 2002;41:15304-15314. [PubMed: 12484769]

23. Kornyushyna O, Burrows CJ. Biochemistry 2003;42:13008-13018. [PubMed: 14596616]

24. Einolf HJ, Schnetz-Boutaud N, Guengerich FP. Biochemistry 1998;37:13300-13312. [PubMed: 9748338]

25. Kamath-Loeb AS, Hizi A, Kasai H, Loeb LA. J Biol Chem 1997;272:5892-5898. [PubMed: 9038207]

26. Mildvan AS, Weber DJ, Abeygunawardana C. Adv Enzymol Relat Areas Mol Biol 1999;73:183207. [PubMed: 10218109]

27. Mishima M, Sakai Y, Itoh N, Kamiya H, Furuichi M, Takahashi M, Yamagata Y, Iwai S, Nakabeppu Y, Shirakawa M. J Biol Chem 2004;279:33806-33815. [PubMed: 15133035]

28. Tassotto ML, Mathews CK. J Biol Chem 2002;277:15807-15812. [PubMed: 11856756]

29. Steenken S, Jovanovic SV, Bietti M, Bernhard K. J Am Chem Soc 2000;122:2372-2374.

30. Moran S, Ren RX, Kool ET. Proc Natl Acad Sci U S A 1997;94:10506-10511. [PubMed: 9380669]

31. Borowski P, Mueller O, Niebuhr A, Kalitzky M, Hwang LH, Schmitz H, Siwecka MA, Kulikowsk T. Acta Biochim Pol 2000;47:173-180. [PubMed: 10961691]

32. Hayakawa H, Hofer A, Thelander L, Kitajima S, Cai Y, Oshiro S, Yakushiji H, Nakabeppu Y, Kuwano M, Sekiguchi M. Biochemistry 1999;38:3610-3614. [PubMed: 10090747]

33. Hah SS, Kim HM, Sumbad RA, Henderson PT. Bioorg Med Chem Lett 2005;15:3627-3631. [PubMed: 15982874]

34. Doris PA, Oefner PJ, Chilton BS, Hayward-Lester A. J Chromatogr A 1998;806:47-60. [PubMed: 9639880]

35. Jaffe EK, Cohn M. Biochemistry 1978;17:652-657. [PubMed: 23826]

36. Hailer MK, Slade PG, Martin BD, Sugden KD. Chem Res Toxicol 2005;18:1378-1383. [PubMed: 16167829] 


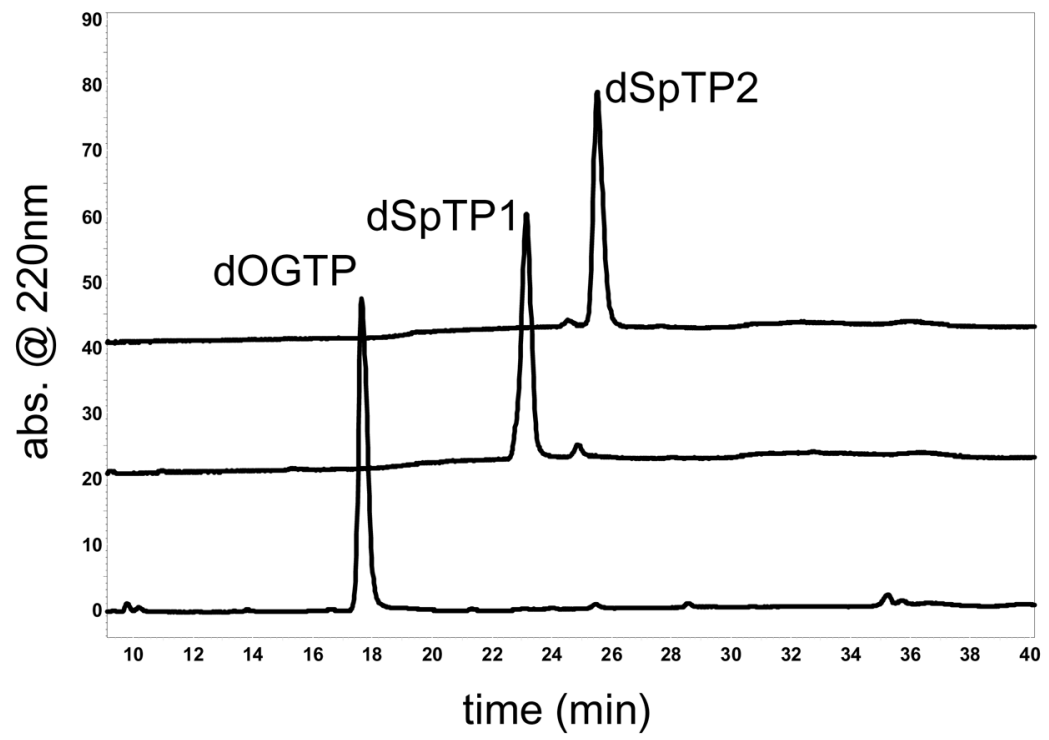

FIGURE 1.

HPLC analysis of purified diastereomers of dSpTP. 


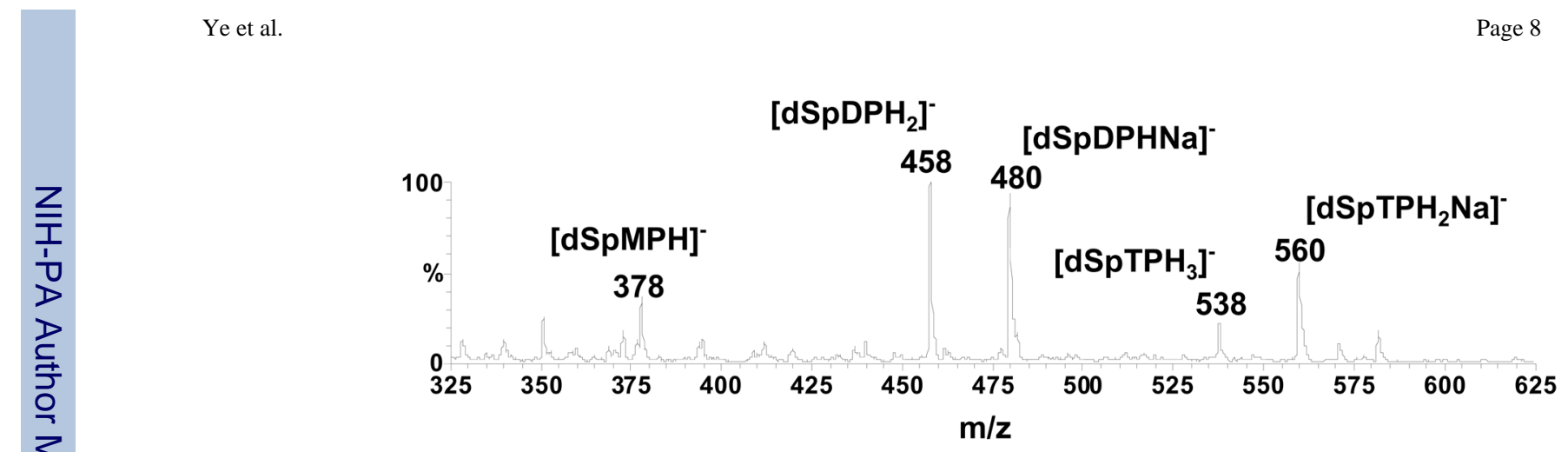

FIGURE 2.

Negative ion ESI-MS analysis of purified dSpTP. 


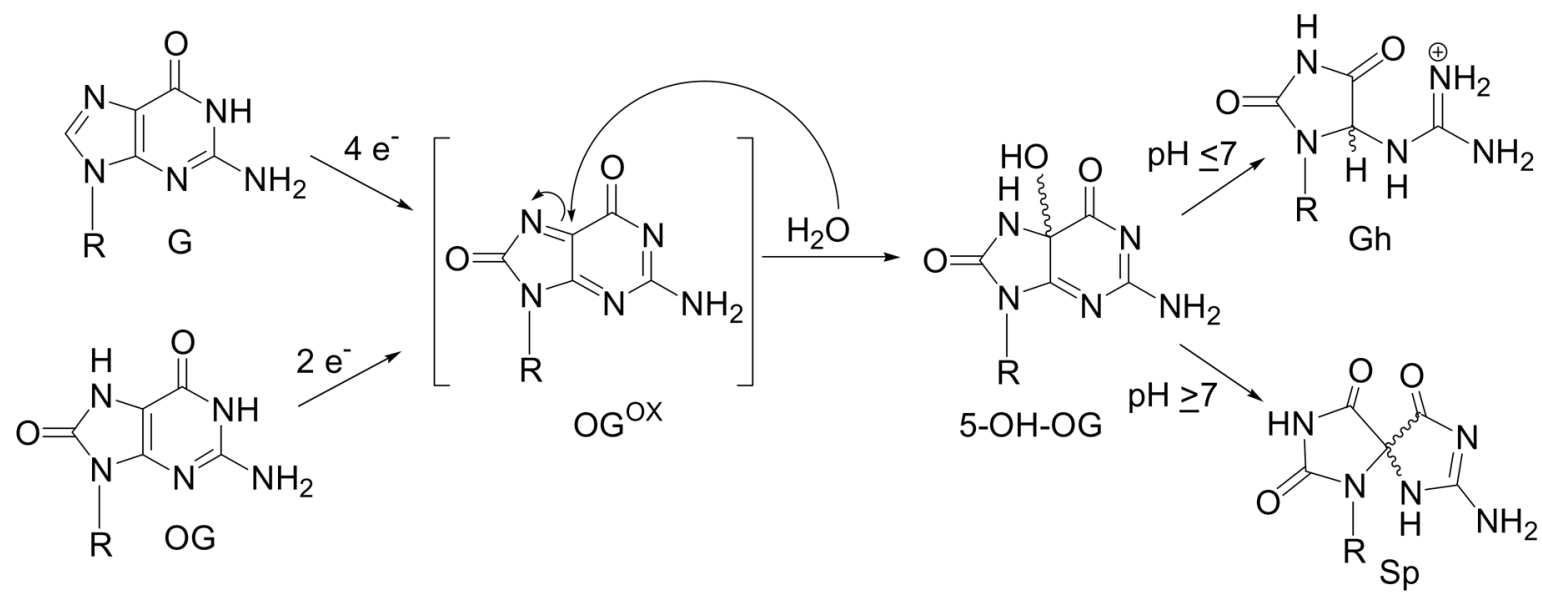

SCHEME 1.

Oxidation Pathways from Guanosine and 8-Oxo-guanosine 


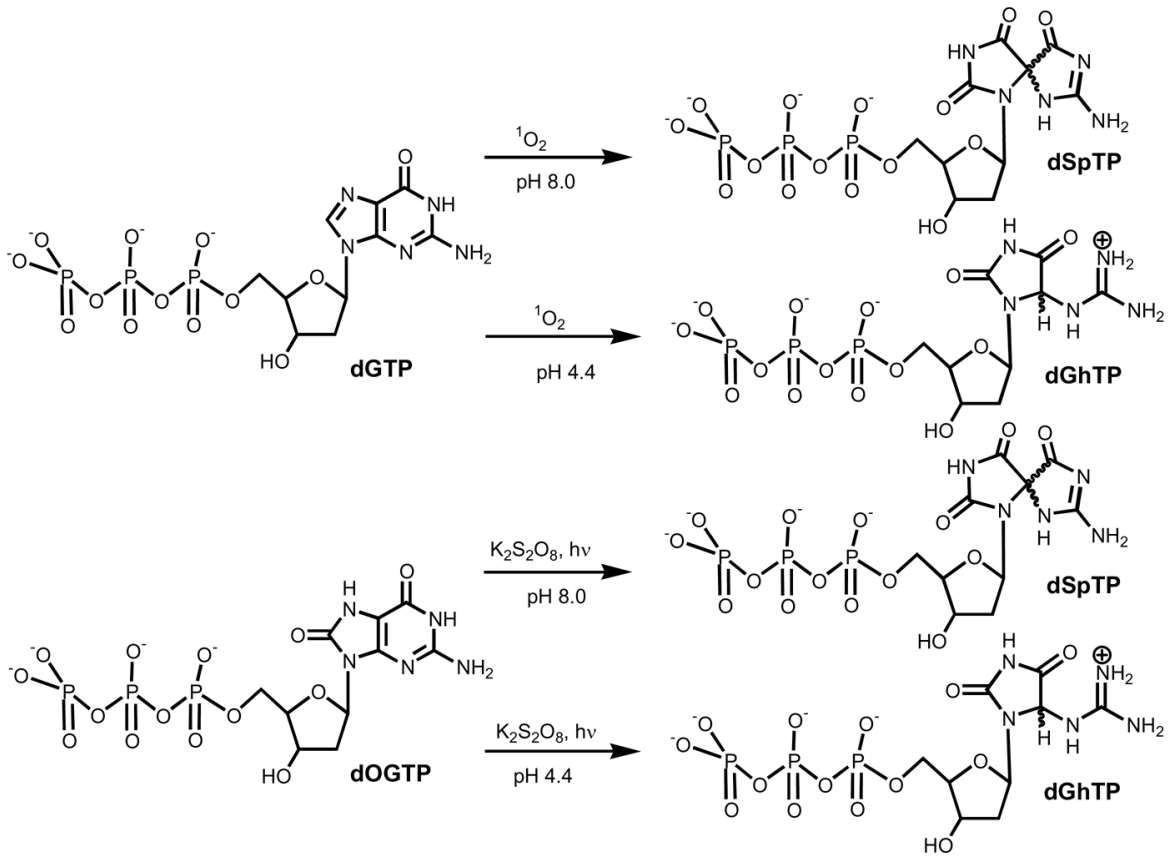

SCHEME 2.

Oxidation Routes from dGTP and dOGTP 